\title{
DE ABANDONO E REDENÇÃO: A AMAZÔNIA NAS PÁGINAS DE EUCLIDES DA CUNHA
}

\section{Alfredo Cordiviola*}

Resumo: Este ensaio analisa alguns dos textos escritos por Euclides da Cunha sobre a região amazônica na primeira década do século XX. Encarregado de chefiar a Comissão de Reconhecimento do Alto Purus, durante seis meses e meio, o engenheiro percorre os rios Purus e Acre, e esboça suas interpretações sobre as terras "à margem da história". Nessas interpretações, instaura-se uma permanente tensão entre as possibilidades de concretização de grandes projetos e as ameaças de fracasso e abandono promovidas por uma natureza conspirativa e por poderes públicos omissos. Entre o otimismo e a fatalidade, Euclides oferece a sua particular visão da utopia, uma utopia antinômica, questionada no momento mesmo de ser enunciada, sempre possível e sempre incerta.

Palavras-chave: Euclides da Cunha. Amazônia. Utopia.

Um esquecido geógrafo americano imaginou alguma vez que os rios eram como os seres humanos, pois, como estes, estavam sujeitos a um ciclo vital que os levava do nascimento até a morte. Nas águas que nunca eram duas vezes a mesma água, o geógrafo Morris Davis imaginava ver as vacilações da infância, a imperícia da juventude, as forças da plena madurez e os lânguidos ocasos da velhice. Davis inscrevia assim a hidrografia no tempo, na história, deixando sua função eminentemente descritiva e topográfica em segundo plano, para poder pensar o devir dos rios em termos diacrônicos, como se fossem organismos sujeitos à mutação e à decadência.

É quase certo que (entre nós, pelo menos) o geógrafo teria sido absoluta e definitivamente esquecido, junto com as suas extravagantes teorias, se não fosse por uma rápida, ocasional, menção

* Doutor pela Universidade de Nottingham, Inglaterra. Professor adjunto do Departamento de Letras da Universidade Federal de Pernambuco. 
que Euclides da Cunha lhe reserva em artigo publicado em 1908, sob o título de "Um rio abandonado". Tomando certa distância das postulações de Davis, Euclides afirma que o método do americano consistia em descrever

dramaticamente as complexas vicissitudes da existência milenária dos fartos cursos de água, mostrando-no-los com uma infância irrequieta, uma adolescência revolta, uma virilidade equilibrada e uma velhice ou uma decrepitude melancólica, como se eles fossem estupendos organismos, sujeitos à concorrência e à seleção, destinados ao triunfo, ou ao aniquilamento, consoante mais ou menos se adaptam às condições exteriores. $^{1}$

Euclides considera tal teoria apenas como "uma rush atrevida da imaginação e da fantasia nos remansos da ciência", e prefere deter-se na evolução geológica e no cuidadoso relevo das características do rio Purus, objeto do seu estudo. Mas as idéias, presentes nas doutrinas de Davis, da mudança permanente, da marca indelével do tempo na superfície escorregadia e ilusória das águas, e dos "choques seculares" que se adivinham no curso, permitem por contraste ao engenheiro esboçar as bases da sua interpretação dos destinos de toda a bacia amazônica.

Depois da consagração como autor d'Os Sertões, em 1904, Euclides fora designado pelo Ministério das Relações Exteriores para chefiar a Comissão mista de reconhecimento do Alto Purus, que tentava estabelecer as fronteiras nacionais e dirimir possíveis conflitos de soberania com as nações vizinhas. Após visitar Belém e Manaus, começa a sua viagem pelos rios Purus e Acre, que lhe demandará seis meses e meio, de abril a outubro de 1905 . Era a grande oportunidade de conhecer um outro Brasil, misterioso e remoto, sobre o qual já lera tantas crônicas de viajantes, ensaístas e naturalistas. Esse outro Brasil, aluvial e intangível, que fora descrito, em um "deslumbrante ciclo quase mitológico" pelos aventureiros do século XVI como Orellana e

Euclides da Cunha "Rios em abandono", em Um Paraíso perdido. Ensaios Amazônicos. Brasília: Senado Federal, 2000, p. 131. Todas as citações de Euclides foram extraídas desse volume. 
Raleigh, e que, a partir da ilustrada Viagem Filosófica de Alexandre Rodrigues Ferreira no XVIII e das românticas visões da natureza sulamericana de Humboldt, fora finalmente aberto "às mais imaginosas hipóteses da ciência" pelas missões e expedições do oitocentos como as de Bates, Wallace, Castelnau, Chandless e Agassiz. Um país que, apesar dos relatos e das indagações, continuava sendo um grande signo de interrogação no pensamento nacional.

Uma tentativa de responder algumas dessas interrogações teria sido Um Paraíso Perdido, o livro que Euclides nunca chegaria a escrever sobre a região. Em seu lugar, perduram os dois volumes que recolhem suas observações e estudos, Contrastes e confrontos (1907) e À margem da história (1909, edição póstuma), o relatório oficial sobre o Purus, artigos diversos, mapas, cartas e entrevistas, todos produzidos entre 1898 e 1909. Na conhecida carta a Artur Lemos, escrita em Manaus em 1905, pouco antes de iniciar a navegação pelo Purus, Euclides parece reconhecer já que a tarefa de escrever sobre a Amazônia é tão elusiva quanto o próprio objeto:

Se escrevesse agora esboçaria miniaturas do caos, incompreensíveis e tumultuárias, uma mistura formidável de vastas florestas inundadas e de vastos céus resplandecentes. Entre tais extremos está, com as suas inúmeras modalidades, um novo mundo que me era inteiramente desconhecido... Além disso, esta Amazônia recorda a genial definição de espaço de Milton: escondese em si mesma. O forasteiro contempla-a sem a ver através de uma vertigem. Ela só lhe aparece aos poucos, vagarosamente, torturantemente. ${ }^{2}$

Euclides teme ser apenas "um escritor esmagado pelo assunto", mais um que fracassa perante a infinidade do verde e do abandono. O Amazonas está sempre "em busca de outras latitudes"; é um "território em marcha",, que desfigura superfícies, arrasta e cria formas, arqueaduras, deltas, que em breve são também deslocados pelas massas de águas barrentas. Para começar a elucidar essa infinita região que surgia como enigma arrevesado e insolúvel, qual, parece 
perguntar o autor, a possibilidade da palavra, da escrita, da sintaxe?; que tipo de escrevente seria mais apto para empreender essa tarefa, um sábio, um artista ou nenhum dos dois? Como, afinal, predicar afirmações e interpretações de uma terra "fantástica e incompreensível", que "esconde-se em si mesma"?

Uma alternativa, precária e parcial, como todas as que a região oferece, é mencionada por Euclides nessa mesma carta a Artur Lemos: "Escreverei um Paraíso Perdido, por exemplo, ou qualquer outro em cuja amplitude eu me forre de uma definição positiva dos aspectos de uma terra que, para ser bem compreendida, requer o trato permanente de uma vida inteira."

Em busca dessa "definição positiva", Euclides parte para cumprir a missão encomendada. Nos percalços da travessia, surge então o observador rigoroso e precavido. Anota cuidadosamente as milhas percorridas, os níveis da vazante, o número das cachoeiras e os declives do curso, como quando descreve um dos afluentes do Purus, o rio Cujar:

em todo o extenso traçado de 1667 milhas que vai da última forquilha até o Amazonas, onde uma diferença de nível de 265 metros aproximadamente determina um desnivelamento insensível de $1 \mathrm{~m} / 11,650 \mathrm{~m}$ ou $0 \mathrm{~m}$, por milha. Mas da confluência do Cujar-Curiúja para cima, a subida acentua-se incisivamente. Assim a diferença de 154 metros de altura, da foz do Cavaljani sobre a do Cujar, indica um declive de $1 \mathrm{~m} / 613 \mathrm{~m}$ ou 3 metros por milha; e a de 35 metros da confluência do Pucani sobre a última, uma queda de nível aproximadamente igual, por milha. ${ }^{6}$

Os números são necessários para traçar mapas e indispensáveis para estabelecer limites, objetivos principais da comissão de reconhecimento. O relatório impõe o rigor do cálculo e a presença de dados e medidas. Mas Euclides sabe ver na sua viagem muito mais do que um território a

Idem, "O inferno verde", op.cit., p. 346.

Idem, "Carta a Artur Lemos",op.cit., p. 378.

Idem, "O rio Purus e seus afluentes", op.cit., p. 260. 
ser medido e catalogado. A região do Purus era apenas uma parcela menor de um todo que parecia estar além de toda consideração, mas essa parte, um mundo em si mesmo, ainda mais remoto e controverso, serve para que o engenheiro possa estabelecer uma relação tensa e incompleta com os vários mundos que se superpõem na região. O Purus-Acre é uma sinédoque desse outro universo que se estende "entre o Madeira e o Javari", que por sua vez é uma sinédoque de uma "Amazônia" captada em plena mutação, mas que pode ser aludida unicamente mediante metonímias. São, para Euclides, mundos em abandono, mas que, apesar de tudo, são capazes de pressagiar - e estariam pressagiando já - futuros extraordinários. Amazônia é para Euclides muito mais do que uma terra que deve ser incorporada pelos fluxos civilizacionais da nação. Era nesse então apenas uma página em branco ou pobremente escrita, mas, era, já nesse momento, uma página que ainda estava por ser escrita. Não qualquer página, nem escrita de qualquer modo, segundo anuncia a célebre definição esboçada em 1907, no prólogo a O Inferno Verde de Alberto Rangel: "Realmente, a Amazônia é a última página, ainda a escrever-se, do Gênese.",

É uma boa definição de utopia, que Euclides sugere sem jamais mencionar a palavra "utopia": uma página que ainda está a escrever-se, que deve ser escrita, e que, quando for escrita, virá para encerrar um ciclo, histórico ou quiçá cósmico. Utopia pode ser definida como aquele lugar que apenas pode ser pensado, porque não existe (salvo no pensamento) e talvez nunca exista. É aquele lugar que apenas pode ser vislumbrado como uma imagem que se imprime sobre o incerto futuro, uma imagem especular, invertida, mas nunca equivalente, criada pelas falências do presente. Mas, na trama de discursos que ao longo dos séculos vão dando sentidos a isso que chamamos "Brasil", há certos momentos, como este que estamos analisando em Euclides, em que a utopia parece se materializar em um aqui e agora iridescente e transitório. Nesses casos, é como se a utopia deixasse de ser formulação e programa, para passar subitamente a adquirir o estatuto daquilo que pode ser descrito, analisado e não já apenas imaginado ou desejado. Trata-se, contudo, de descrições e análises fugazes, necessariamente condicionadas pelo assombro e pela

${ }^{7}$ Idem, "O inferno verde", op.cit., p. 346. 
dúvida, e ameaçadas quiçá pela suspeita de que essa situação auspiciosa venha a desaparecer antes mesmo de que o analista possa publicá-la e exaltá-la. Trata-se de uma utopia que o presente parece estar confirmando, mas confirmando apenas como promessa. Uma promessa movida por essa força locucionária que, como em todas as promessas, afirma no ato da enunciação a existência de um futuro perpetuamente situado entre a probabilidade e o fiasco.

Estabelecem-se assim dois modos de relações marcadas pela antinomia; a primeira, que surge entre um presente falido e um outro presente, capaz de reunir as condições para a cristalização da utopia. A segunda, espelhada inversamente na anterior, entre o futuro em que a promessa finalmente se cumpre e esse outro futuro, do fracasso e da desilusão, que poderia estar aguardando à espreita. Esses dois eixos temporais (dois presentes e dois futuros em permanente atrito) percorrem, com suas convergências e distanciamentos, todo o conjunto dos textos escritos por Euclides sobre a Amazônia, e criam a vasta rede de significações que definem esse perdido paraíso como um território hostil e, ao mesmo tempo, generoso e hospitaleiro, como uma espécie de cemitério de ruínas e decrepitude e, ao mesmo tempo (o tempo da escritura), como espaço promissor, onde, como Humboldt tinha previsto, "mais cedo ou mais tarde se há de concentrar a civilização do globo". 8

A máquina interpretativa de Euclides parece depender plenamente do funcionamento desses eixos, que operam em permanente tensão. Assim, ao representar o presente, longe de idealizar a paisagem, o autor descreve cruamente as agruras e estorvos da ingrata região. (De fato, a própria noção de "paisagem" parece estar ausente nesses textos, pois esta supõe observação à distancia e composição, duas propriedades que a região, por estar sempre em estado de mudança e sempre avançando sobre o observador, nega de maneira constante). Há muitas páginas que poderiam ser consideradas verdadeiras fichas criminais da natureza amazônica, prontuários de perversidade natural, como, por exemplo, esta que dedica às margens do Purus:

8 Idem, "Entre o Madeira e o Javari", op.cit., p. 220. 
Aqueles longínquos lugares do Purus (...) exigem uma aclimação dificílima e penosa. Apesar de um rápido povoamento, de cem mil almas em pouco mais de trinta anos, têm ainda o caráter nefasto das paragens virgens onde a copiosa exuberância da vida vegetal parece favorecida por um ambiente impróprio à existência humana. O seu quadro nosológico assombra, pela vasta série de doenças, que vão das maleitas permanentes à hipoêmia intertropical entorpecedora e àquela originalíssima "purupuru" que não mata mas desfigura, embaciando a pele do selvagem e dando-lhe um fáceis de cadáver, pondo no rosto do negro, salpintado de manchas brancas, uma espantada máscara demoníaca, e imprimindo no do branco a brancura repulsiva do albinismo[...]. ${ }^{9}$

Essa é a Amazônia fatal, que destrói e constrói para volver a devastar, que expulsa os homens ou os transforma em "homúnculos da civilização". A Amazônia que a todos ilude, "sem destino, sem tradições e sem esperanças" "10 dos seringueiros escravizados e das “tristonhas 'entradas' dos seringais." Essa mesma região, onde tudo parece ser "vacilante, efêmero, antinômico, na paragem estranha onde as próprias cidades são errantes, como os homens, perpetuamente a mudarem de sítio, deslocando-se à medida que o chão lhes foge roído das correntezas, ou tombando nas "terras caídas" das barreiras...,",11 para Euclides oferece, entretanto, como nenhuma outra no país, possibilidades infinitas, que parecem estar se concretizando já em certos pontos de promissão. É o caso do Acre:

em menos de trinta anos, o Estado que era uma vaga expressão geográfica, um deserto empantanado a estirarse, para sudoeste, definiu-se de chofre, avantajando-se aos primeiros pontos do nosso desenvolvimento econômico. A sua capital - uma cidade de dez anos

\footnotetext{
9 Idem, "Contra os caucheiros", op.cit., p. 212.

10 Idem, "Entre os seringais", op.cit., p. 336.

11 Idem, "Impressões gerais", op.cit., p. 124.
} 
sobre uma tapera de dois séculos - transformou-se na metrópole de maior navegação fluvial da América do Sul. E naquele extremo sudoeste amazônico, quase misterioso [...] cem mil sertanejos, ou cem mil ressuscitados, apareciam inesperadamente e repatriavamse de um modo original e heróico; dilatando a pátria até aos terrenos novos que tinham desvendado. ${ }^{12}$

O engenheiro não evita os tons épicos para descrever o povoamento da vasta faixa encerrada entre os rios Purus e Juruá, que transforma remotos "waste of waters" em avançadas do progresso. Percebe nas migrações internas o impulso tumultuoso e avassalador capaz de criar cidades a partir das quais possam ser multiplicados os benefícios da civilização, atraindo também estrangeiros de todas as nacionalidades: "lá vivem todos, agitam-se, prosperam-se e acabam longevos". Para Euclides, o exemplo mais claro dos poderes regenerativos que uma cidade pode propagar nessas latitudes está na fundação de Lábrea, nas margens do Purus.

Uma cidade, uma verdadeira cidade, trazendo desde o nascer um caráter destoante de nossos povoados sertanejos - com o requinte progressista de uma imprensa de dois jornais, O Purus e O Labrense, e o luxo suntuário de um teatro concorrido, e colégios, e as ruas calçadas e alinhadas: a molécula integrante da civilização aparecendo, repentinamente, nas vastas solidões selvagens $[\ldots]{ }^{13}$

Isto foi escrito em 1904; hoje, a cidade de Lábrea parece ser um traço esquecido na lisura dos mapas. A cidade é o ponto final, o non plus ultra solitário e assombrado de uma das grandes epopéias falidas dos tempos modernos, a rodovia Transamazônica.

Euclides lembra contudo que essa molécula de progresso não aparecera lá por acaso. Se a cidade foi fundada e conseguiu prosperar foi devido ao estabelecimento da Companhia Fluvial do Amazonas, cujos barcos interligavam as áreas distantes e permitiam que as forças

12 Idem, "Um clima caluniado", op.cit. p.150-151.

13 Idem, "Entre o Madeira e o Javari", op.cit., p. 218. 
vivas da ocupação levassem adiante a sua tarefa. Por isso o engenheiro insiste tanto na importância que uma ferrovia Transacriana teria para o desenvolvimento do território. Dedica assim longas páginas para apresentar o projeto de construção da ferrovia, e, lembrando o exemplo dos Estados Unidos, enfatiza os enormes benefícios que aportaria; com o trem, "realizar-se-á em dois dias a viagem de Cruzeiro do Sul ao Acre, que hoje, nas quadras mais propícias, dura mais de um mês". "O valor econômico," prossegue, "daquele traçado é incalculável. E evidencia-se sob múltiplas formas; sendo naturalmente mais dignas de apreço as mais remotas, oriundas do progredimento ulterior, inevitável, da região atravessada"14. Complementando a ação dos rios, pelos quais avançariam os vetores de prosperidade, a estrada de ferro (que teria sido muito mais aproveitável que a trágica linha Madeira-Mamoré, cuja construção estava sendo reiniciada na época) ${ }^{15}$ precipitaria "extraordinários destinos" para toda a geografia amazonense e seria, sobretudo, "uma grande estrada internacional de aliança civilizadora, e de paz"16 capaz de resolver os conflitos fronteiriços e de aprofundar os vínculos com a Bolívia e o Peru.

Porém, para que isso pudesse acontecer, era preciso que houvesse uma forte intervenção dos poderes públicos. "O Purus é um enjeitado", escreve em 1908. "Precisamos incorporá-lo ao nosso progresso, do qual ele será, ao cabo, um dos maiores fatores, porque é pelo seu leito desmedido em fora que se traça, nestes dias, uma das mais arrojadas linhas da nossa expansão histórica." 17 É na nação, na sua determinação ou negligência, onde descansam os futuros da utopia, e da nação dependerá o cumprimento ou a interrupção dos destinos ocultos na vastidão. O futuro então será extraordinário, mas unicamente se são cumpridos certos requisitos que o presente torna imperiosos. Esse é o problema a ser resolvido antes que o abandono venha a se apoderar da terra.

14 Idem, "A Transacriana", op.cit., p. 204

15 Sobre a Madeira-Mamoré, ver Foot Hardman, F. Trem fantasma. A modernidade na selva. São Paulo: Companhia das Letras, 1988.

16 Euclides da Cunha, "A Transacriana", op.cit., p. 208.

17 Idem, "Rios em abandono", op.cit., p. 144. 
Mas Euclides sabe muito bem que, "pela indiferença dos poderes públicos," o povoamento da Amazônia estivera "largos anos aberto à intrusão de todas as moléstias e de todos os vícios"18. Mesmo assim, perante o abandono oficial, adivinha ainda a existência de uma força superior, o clima, que, ao longo das décadas, e apesar de tudo,

exercitou uma fiscalização incorruptível, libertando aquele território de calamidades e desmandos, que seriam, além de toda a proporção, muito maiores dos que ainda hoje lá se observam. Policiou, saneou, moralizou. Elegeu e elege para a vida os mais dignos. Eliminou e elimina os incapazes, pela fuga ou pela morte. E é certo um clima admirável o que prepara as paragens novas para os fortes, para os perseverantes e para os bons. $^{19}$

É como se Euclides pudesse antever no clima a força corretória e punitiva por excelência, o braço armado dos sólidos desígnios da seleção natural. Contra os vícios, contra as negligências públicas e privadas, ainda permanece o clima para garantir que, no futuro, as promessas possam ser cumpridas. O clima é a maior expressão da Vontade da natureza, dessa natureza, que, na Amazônia, apenas se deixa ser percebida por "olhos deslumbrados e vazios" 20 , e que se apresenta como inesgotável reserva de segredos e multiplicadora de ruínas ao mesmo tempo, todo o tempo. Parece contraditório que um publicista das virtudes do capital e do trabalho acabe depositando suas últimas e mais firmes esperanças na ação da natureza, mas essa contradição poderia ser entendida à luz de uma certa idéia de nação que Euclides construiu na sua obra: uma nação como projeto, uma nação do futuro, cujas virtualidades resistem e resistirão apesar de e contra os erros históricos, os atrasos e a incúria. Como em Canudos, entre a confiança positivista (os milagres possíveis da ciência e da técnica) e as "cesuras do real" 21 (as carências da história e do presente), estabelece-se um particular contraponto, que se duplica em

\footnotetext{
18 Idem, "Um clima caluniado", op.cit., p. 157.

19 Idem, ibidem, p. 157.

20 Idem, "O inferno verde", op.cit., p. 344.

21 Ver Foot Hardman, op. cit., p 229.
} 
abismo nessa percepção da natureza como essência fatal (porque parece estar sempre conspirando contra os desígnios do progresso) e redentora (porque concentra e preserva as bases e atributos de uma nação futura).

Afirmando os poderes dessa última garantia oferecida por um meio natural hostil e aniquilador, mas sempre portentoso e disposto a possibilitar outras redenções, Euclides se inclui nessa longa lista de observadores que advertiram na natureza brasileira as condições para a realização da utopia. Utopias maiores ou menores, mas sempre latentes - e portanto sempre viáveis - são uma constante nas páginas dos viajantes do século XIX. Em muitas dessas crônicas parece haver um certo padrão de observação, que opera através da sobreposição de descrições e visões, e transita entre a materialidade da informação e as prospecções da inferência, ou, como diria Barthes sobre Michelet, entre os excessos de precisão e os excessos de evanescência (1987: 180-7). O quadro se desenvolve assim mediante certas unidades de sentido que formam uma morfologia narrativa recorrente: o viajante percorre o território, com a autoridade que lhe confere a experiência, identifica o local propício, analisa cuidadosamente suas condições atuais e suas potencialidades e projeta futuros auspiciosos e, aparentemente, inquestionáveis. Como se todos esses fatores estivessem unidos por relações causais e necessárias, configura-se uma sequiência lógica validada pela perspicácia do analista e pelos favores do prognóstico.

Nessas crônicas de viagem do XIX, essa seqüência aparece estreitamente vinculada ao curso dos rios, em cujas margens se adivinham as perspectivas futuras de toda uma região. Assim, são principalmente as grandes vias fluviais da Amazônia, do centro-oeste e o São Francisco as que motivaram os mais venturosos cálculos. Para citar apenas um exemplo, que guarda muitas semelhanças com as propostas de Euclides, poderíamos mencionar os estudos dos naturalistas bávaros Johann Spix e Karl Martius sobre a bacia amazônica feitos entre 1817 e 1820.

Em Viagem pelo Brasil (publicado entre 1823 e 1831), Spix e Martius, após terem percorrido grande parte do país, examinando a flora, a fauna, a geologia, os aspectos sociais, históricos e econômicos, e estudando as populações indígenas, chegam a Belém e iniciam a viagem pelos rios Amazonas, Solimões, Negro Japurá, e Madeira. 
Quase um século antes da incursão de Euclides pelo Purus, os naturalistas alemães, a modo de conclusão do percurso amazônico, descrevem uma visão que bem poderia ter sido subscrita pelo engenheiro:

Que maravilhosas perspectivas não se oferecerão quando algum dia as margens do majestoso rio forem ocupadas por cidades populosas, quando as terras a oeste tiverem transposto os limites naturais dos Andes, e estradas reais da capital do Peru ao Marañon ligarem o Oceano Pacífico com o Atlântico, quando as matas, hoje melancólicas e solitárias, à margem do Cassiquiare, ressoarem aos clamores dos navegantes vindos do Orinoco para o Amazonas, quando forem navegáveis as cachoeiras do Madeira, furados os divisores de água de Aguapeí e Camapuão, e quando as mesmas velas, das águas sossegadas do Rio Negro e do imponente Amazonas, se desdobrarem pacíficas no Prata cheio de vida.

Com prazer, demora o olhar do filantropo nessa visão de auspicioso futuro, quando civilização e natureza tiverem criado no mais opulento país do mundo (que traz em si todas as condições) uma pátria de feliz raça humana, cuja atividade e bem-estar reciprocamente se compensarão (SPIX.; MARTIUS, 1981, p. 306).

Nesse exaltado otimismo, ecoam os vaticínios feitos por Alexander Humboldt alguns anos antes. Otimismo que, do mesmo modo, haverá de retinir cinquienta anos depois nos escritos e relatórios de um William Haldfeld ou de um Richard Burton relativos ao São Francisco, ou, já na República, nas astuciosas considerações que aparecem em Nas selvas do Brasil, feitas por Theodore Roosevelt após sua viagem junto ao Marechal Rondon. Entre esses autores, parece haver uma coincidência, a de entender a modernidade como imperativo. Rios, estradas, ferrovias são as grandes marcas que se imprimem sobre a terra ainda vazia, emblemas vertiginosos e quase míticos do ímpeto modernizador, que anulam os passados e instauram o définitivo salto do progresso. Imaginárias vias, pensadas para escoar riquezas e promover migrações, cujos eventuais percursos permitiriam prenunciar o surgimento de prósperas cidades e a sua integração com 
os principais centros urbanos e portos do país. Contudo, sem trepidações nem locomotivas, sem a transformação dos rios em canais plenamente navegáveis, e sem a criteriosa intervenção do quimérico poder público, por ora o que existe nas páginas desses publicistas daquilo que Andreas Huyssen denomina "futuros presentes" (2000, p. 9) é uma modernidade vista sempre ao longe, voltada inteiramente para o devir. Uma modernidade que é apenas aspiração e desejo e que, portanto, perdura (como projeção e sonho) sob as ameaças da frustração e do acaso. Uma modernidade que, já no mesmo momento de ser enunciada e anunciada, passa a adquirir a ilusória solidez de um fatum, palavra que alude a oráculos e predições, mas também ao destino, à fatalidade, à desgraça e à sorte.

Quiçá nessa palavra, que supõe a menção do futuro (um futuro sempre incerto e sujeito a fortuitas e emaranhadas condições: um futuro questionado) esteja contida a tensão implícita em toda utopia, essa tensão, impossível de ser resolvida na esfera do discurso, entre a concretização e o colapso. Ao enunciar o que pode ou deve acontecer, a utopia refere, como desvio e fantasmagoria, aquilo que pode não acontecer, aquilo que quiçá nunca aconteça, e que está sempre minando, silencioso e inquieto, as postulações e certezas do projeto. Essa modulação, que não está ausente das páginas dos autores mais esperançosos e confiantes no futuro da nação, parece acompanhar o tempo todo as representações de Euclides. Mesmo quando enfatiza, como vimos, as imensas potencialidades da bacia amazônica, o engenheiro continua lidando com essa sombra, que lhe mostra apenas desolação e abandono. Sombra que aparece mencionada muitas vezes, mas que em um dos seus textos em particular se corporiza e ganha dimensões excepcionais. Refiro-me ao artigo intitulado "Judas Asvero".

Trata-se, como é sabido, de um dos seus mais memoráveis escritos. Para Euclides, os seringueiros do Purus fatalmente sabem que estão condenados. Não se rebelam; apenas se resignam, perante uma ordem natural e social que não entendem e que os excede:

Então pelas almas simples entra-lhes, obscurecendo as miragens mais deslumbrantes da fé, a sombra espessa de um conceito singularmente pessimista da vida: certo, o redentor universal não os redimiu; esqueceu-os para sempre, ou não os viu talvez, tão relegados se acham à 
borda do rio solitário, que no próprio volver das suas águas é o primeiro a fugir, eternamente, àqueles tristes e desfreqüentados rincões. ${ }^{25}$

São sombras espessas, perdidas nas estradas da floresta. Uma vez ao ano, contudo, eles têm também uma chance de expiação. No sábado de Aleluia, os seringueiros criam bonecos, homúnculos de trapos e ruína, para lembrar a traição de Judas. Os simulacros são depois levados em barcas pela correnteza, para que os ribeirinhos possam descarregar suas espingardas e suas fúrias sobre a triste figura. Euclides vê nesse ato uma cerimônia melancólica e inútil, uma espécie de teatro da desventura. É, para o seringueiro, apenas um "doloroso triunfo": "O sertanejo esculpiu o maldito à sua imagem. Vinga-se de si mesmo: pune-se, afinal, da ambição maldita que o levou àquela terra". Mas essa catarse é incapaz de promover mudanças, não revela nada ao seringueiro, confirma apenas a sua própria perdição. "Sem destino e sem fim," o errante espectro encontra no seu caminho outros espantalhos que são levados pela correnteza: "Aliam-se-lhe na estrada dolorosa outros sócios de infortúnio: outros aleijões apavorantes sobre as mesmas jangadas diminutas entregues ao acaso das correntes, surgindo de todos os lados, vários no aspecto e nos gestos",26. O escárnio a Judas é apenas a representação cíclica de uma deriva que parece atingir a todos os habitantes da região, e também a toda a região, que permanentemente muda, desestabiliza e corrói as precárias avançadas do progresso. Como os homens, os mesmos rios parecem estar desorientados, começando pelo Amazonas:

A inconstância tumultuária do rio retrata-se ademais nas suas curvas infindáveis, desesperadoramente enleadas, recordando o roteiro indeciso de um caminhante perdido, a esmar horizontes, volvendo-se a todos os rumos ou arrojando-se à ventura em repentinos atalhos [...] sempre desordenado e revolto, e vacilante, destruindo e construindo, reconstruindo e devastando, apagando numa hora o que erigiu em decênios - com a ânsia, com a tortura, com o exaspero de monstruoso artista

Euclides da Cunha, "Judas Asvero", op.cit., p. 174. Ibidem, p. 178. 
Por esses rios que, para Euclides, contavam com extraordinários destinos, pelos rios em cujas margens poderiam surgir cidades industriosas, e que conduziriam à paz entre as nações, passa também esse exército de efígies em pena. Em procissão, vacilantes, vão descendo, "descendo, descendo vagarosamente, descendo," segundo a litania que o engenheiro repete ao logo da sua crônica. Como os Judas, os seringueiros do Purus são o reverso de toda utopia, o limite contra o qual a palavra utópica se revela inútil, por ser apenas isso, palavra.

A procissão do sábado de Aleluia é a desesperançada glosa de todos os projetos, de todas as medições, de todas as ilusões. Mas, por outro lado, é também o espetáculo que obriga a postular outros futuros e a inventar outras utopias para a Amazônia, essa terra que ainda não passava de ser um quadro incompleto, indefinido, que estava à margem da história, mas onde seria escrita a última página do Gênese. Porque se, nos textos de Euclides, os rios amazônicos, "destruindo e construindo, reconstruindo e devastando", costumam aniquilar a palavra utópica, são capazes também de trazê-la sempre de volta, em flutuação vagarosa, para que possa ser vista mais uma vez, muitas outras vezes.

\section{Referências}

BARTHES, Roland. O rumor da língua. Lisboa: Edições 70, 1987.

CUNHA, Euclides da. Um paraíso perdido. Ensaios Amazônicos. Brasília: Senado Federal, Conselho Editorial, 2000.

FOOT HARDMAN, Francisco. Trem fantasma: a modernidade na selva. São Paulo: Companhia das Letras, 1988.

HUYSSEN, Andreas. Seduzidos pela memória. Rio de Janeiro: Aeroplano, 2000.

SPIX, Johann; MARTIUS, Karl. Viagem pelo Brasil. 1817-1820. Belo Horizonte: Itatiaia, 1981. 3 v.

WEINBERG, Gregorio. La ciencia y la idea de progreso en América Latina, 1860-1930. Buenos Aires: Fondo de cultura económica, 1988.

27 Ibidem, p. 123. 